\title{
Have City Dwellers Lost Touch with Modern Agriculture? In Quest of Differences between Urban and Rural Population ${ }^{\dagger}$
}

\author{
Andreas Gabriel * $*$ and Markus Gandorfer
}

Bavarian State Research Center for Agriculture, Institute for Agricultural Engineering and Animal Husbandry, Kleeberg 14, 94099 Ruhstorf a.d. Rott, Germany; markus.gandorfer@lfl.bayern.de

* Correspondence: andreas.gabriel@lfl.bayern.de

+ Presented at the 13th EFITA International Conference, online, 25-26 May 2021.

Citation: Gabriel, A.; Gandorfer, M. Have City Dwellers Lost Touch with Modern Agriculture? In Quest of Differences between Urban and Rural Population. Eng. Proc. 2021, 9, 25. https://doi.org/10.3390/engproc 2021009025

Academic Editors: Dimitrios Kateris and Maria Lampridi

Published: 29 November 2021

Publisher's Note: MDPI stays neutral with regard to jurisdictional claims in published maps and institutional affiliations.

Copyright: (C) 2021 by the authors Licensee MDPI, Basel, Switzerland. This article is an open access article distributed under the terms and conditions of the Creative Commons Attribution (CC BY) license (https:/ / creativecommons.org/licenses/by/ $4.0 /)$.

\begin{abstract}
Frequently, urbanization and loss of an urban population's connection to agriculture are given as the main reasons for decreasing societal acceptance of modern-day agriculture. An online survey of the German population in 2018 provided two selective subsamples of rural $(n=337)$ and urban residents $(n=560)$. Comparing group differences with regard to (a) the general societal perspective on agriculture and (b) positions on the use of digital farming technologies shows only little evidence of significant contributions of the used predictor items. Thus, no generalized tendency can be found that city dwellers are more opposed to agricultural developments based on different attitudes and perceptions.
\end{abstract}

Keywords: attitudes; digital farming technologies; modern agriculture; rural; urban

\section{Introduction}

Urban society's knowledge of, understanding of, and relationship to modern agriculture is highly questioned by various agricultural stakeholders in Germany. In agricultural media, these issues are increasingly being taken up and discussed with politicians and the agricultural and food industry with regard to how to deal with the urban-rural discrepancy. Frequently, urbanization and loss of an urban population's connection to agricultural production are given as the main reasons for the perceived differences. Due to assumed alienation from the agricultural sector of people living in urban areas, it seems difficult to reconcile the benefits and legitimization of modern agricultural production with related social and environmental issues (e.g., animal welfare, insect mortality).

Nowadays, more than three quarters of the German population live in urban settlement areas [1]. Whereas at the beginning of the last century almost $40 \%$ of the population practiced agriculture themselves, less than $2 \%$ are currently employed in agriculture and related sectors [2]. Nevertheless, people are also consumers who are becoming increasingly responsible and sophisticated when it comes to transparent and sustainable food production [3]. Easier and faster access to information and higher media attention accelerate this process. The current literature does not clearly indicate whether attitudes toward and perceptions of contemporary agriculture differ between urban and rural populations $[4,5]$. However, there is evidence that the physical distance of urban dwellers from agriculture affects their knowledge on agriculture [6]. Many stakeholders and decision makers in the agricultural sector attribute agriculture's image problems to the disconnection of society from modern agriculture. However, is urbanization really the main reason for the lack of societal acceptance?

\section{Materials and Methods}

To explore this question, we draw on data from a 2018 online consumer survey querying societal acceptance of digital farming technologies. In addition to partially pre-quoted information on the sociodemographics of 2012 respondents, several items 
were asked about general attitudes toward agriculture, self-assessed knowledge about agricultural production processes and equipment, and trust in farmers' responsible acting. Furthermore, we investigated respondents' attitudes toward digital farming technologies (DFT) using Likert scales. Additionally, the survey participants should give spontaneous short associations with four shown pictures of digital technologies in practice (milking robot, cow-feeding robot, autonomous tractor sowing, swarm robots on the field). The web sources for the images used can be found in the supplementary material of this article. More details on the surveyed items and pictures can be found in a recent publication by Pfeiffer et al. [7].

For the purpose of this analysis, the population densities of the individual postal code areas were classed on the basis of the official divisions between urban and rural $\left(150,000\right.$ inhabitants per $\left.\mathrm{km}^{2}\right)$. We can thus compare a subsample of 560 respondents who live in larger cities and highly populated areas with a subsample of 337 respondents who live in towns with fewer than 100,000 inhabitants and a low regional population density. Both subsamples were tested for differences in sociodemographic characteristics and in deviation of median responses concerning the queried Likert scales and picture association ratings. Two binominal logistic regression models were designed to indicate the probability of group classification by predictors indicating (a) the general societal perspective on agriculture and (b) positions on the use of digital farming technologies (DFT).

\section{Results}

Members of the urban subsample have a significantly weaker relation to agriculture and show a slightly higher level of education. Differences can be measured in specific statements regarding self-assessed knowledge of current agricultural methods and trust in responsible practice of farmers.

Figure 1 represents the mean values of the two subsamples' responses to each surveyed rating scale. The 5-point scales range from "I fully agree" or "very high" to "I fully disagree" or "very low". Unsurprisingly, regarding self-assessed knowledge, both subsamples are very restrained when it comes to current practice and technology use. In this respect, urban dwellers are even more cautious than the rural population, as shown by the statistical comparison. There are almost no differences between urban and rural residents on statements about general attitudes toward agriculture. Both groups agree with statements on animal welfare, environmental protection, and the life quality of farmers. For the two items concerning trust in farmers' practice, the mean values are more in the middle of the scale range, with the rural population extending more trust to farmers.

A further scale measured different attitudes toward the benefits of digital farming technologies. Differences can be observed between the items but not between the subsamples. Both subsamples agree that the technologies primarily support the farming family and are undecided as to whether new technologies lead to the alienation of farmers from their land or animals. Finally, the mean ratings of the maximum three associations per shown picture were compared on a scale of triple positive to triple negative. Robotics in the context of dairy production was viewed more negatively than robotics in the context of arable farming. In particular, the image of a cow surrounded by a milking robot led to frequent negative associations. The city dwellers are more positive concerning field robotics, while rural residents are less critical when they are confronted with pictures of autonomous animal husbandry technologies.

Two logistic regression models were designed to indicate the probability of classification to the two groups and the explained variance of the indicating predictors. Regarding the first model (social perspective on agriculture), it is found that differences through items of self-assessed knowledge on modern agriculture, attitudes toward agriculture, and trust in farmers offer no explanatory contribution to the classification of the respondents to one of the two groups. For the second model (use of DFT), the variance explained by covariates indicating 'knowledge of agricultural machines', several 'attitudes towards DFT' and 'spontaneous associations' of shown pictures of selected technologies are also low (Table 1). 
Only better knowledge of machines and equipment by the rural population and the respective direction of associations (positive, negative) with pictures of a large autonomous tractor and a feeding robot, respectively, provide statistically significant contribution to the classification. The odds indicate the corresponding probability of classification when changing these parameters by one scale step.

rural (337); urban (560)

My knowledge of present-day agriculture

$\mathrm{K} 1$... of production methods in crop production is...

$\mathrm{K} 2$.... of animal husbandry processes is...

$\mathrm{K} 3$.... of the latest machinery and equipment used in agriculture is...

General attitudes toward farming

G1. Preservation of the environment for future generations is of importance.

G2. Welfare of farm animals is important; this influences my actions.

G3. Family farming structures seem valuable and should be preserved.

G4. I have a fundamentally positive attitude toward agricultural practice.

G5. Farmers should get more free time.

Trust in German farmers

T1. German farmers pay great attention to animal welfare.

T2. German farmers protect our environment.

Attitudes toward the benefits of DFT

A1. ... bring farmers and consumers closer together.

A2. ... enable a more environmentally friendly production

A3. ... lead to alienation of the farmer from soil/ animals.

A4. ... improves the quality of life of the farming family.a)

A5. ... improves animal welfare and animal health

Spontaneous associations with four pictures of $\mathrm{DFT}^{\mathrm{b}}$ )

S1. Autonomous tractor sowing in the field ${ }^{\mathrm{a})}$

S2. Swarm robots sowing in the field

$\mathrm{S} 3$. Cow in milking robot during milking process

S4. Cow-feeding robot during feed provision in the barn

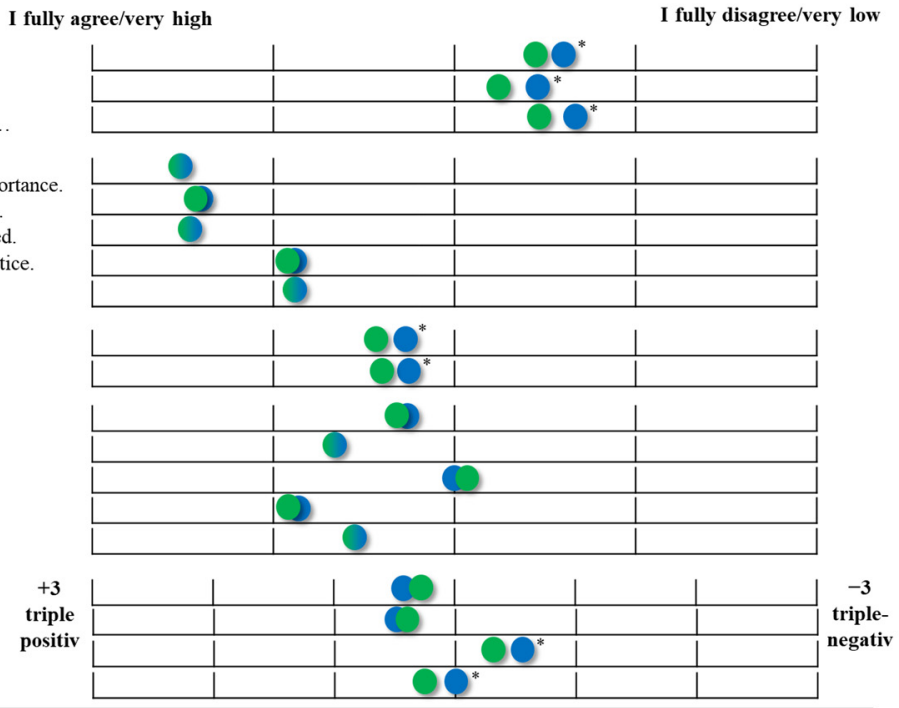

Figure 1. Mean values of subsamples; * = rejection of H0; nonparametric Mann-Whitney U test; (a) unequal variances;

(b) aggregated value of associations from -3 'triple negative' to +3 'triple positive'.

Table 1. Binominal logistic regression model 2: positions on the use of DFT.

\begin{tabular}{|c|c|c|c|c|c|}
\hline Predictors & B & SE & Wald & $p$ & Odds \\
\hline K3. Knowledge of machinery and equipment used & 0.214 & 0.076 & 8.008 & $0.005 *$ & 1.239 \\
\hline A1. DFT brings farmers and consumers closer together & 0.095 & 0.094 & 1.018 & 0.313 & 1.100 \\
\hline A2. DFT enables a more environmentally friendly product & -0.177 & 0.118 & 2.254 & 0.133 & 0.838 \\
\hline A3. DFT leads to alienation of farmers from soil/animals & -0.125 & 0.073 & 2.958 & 0.085 & 0.883 \\
\hline A4. DFT improves the quality of life of a farm family & 0.133 & 0.111 & 1.450 & 0.229 & 1.143 \\
\hline A5. DFT improves animal welfare and animal health ${ }^{\mathrm{T}}$ & 0.437 & 0.427 & 1.046 & 0.306 & 1.548 \\
\hline S1. Autonomous tractor sowing in the field & 0.246 & 0.061 & 5.778 & $0.016^{*}$ & 1.158 \\
\hline S2. Swarm robots sowing in the field & 0.080 & 0.064 & 1.580 & 0.209 & 1.084 \\
\hline S3. Cow in milking robot during milking process & -0.071 & 0.052 & 1.875 & 0.171 & 0.932 \\
\hline S4. Cow-feeding robot during feed provision & -0.180 & 0.059 & 9.351 & $0.002 * *$ & 0.835 \\
\hline Constant & -0.311 & 0.584 & 0.285 & 0.594 & 0.732 \\
\hline
\end{tabular}

$\chi^{2}(10)=33.111, p<0.000 ;$ Nagelkerke's $R^{2}=0.049$ (Cox and Snell $\left.R^{2}=0.036\right)$ | overall percentage of accuracy classifications (contribution of predictor variables $)=63.1 \%(+0.7 \%) \mid{ }^{\mathrm{T}}$ variable was $1 / \mathrm{x}$-transformed due to lacking linearity (tested and assessed using the Box-Tidwell procedure [8]). Bonferroni correction was applied to all 10 model terms [9] ${ }^{*}(p<0.05)$; ${ }^{* *}(p<0.01)$.

\section{Discussion and Conclusions}

The two clearly distinguished subsamples of rural and urban residents reveal differences in the level of education and physical contact with agriculture. In addition, lower rates of self-assessed knowledge and trust in modern agriculture can be shown among city dwellers. City dwellers were also significantly more critical of the images concerning animal husbandry than the comparison group. The two logistic models regarding general societal perspective on agriculture and positions on the use of digital farming technologies, however, show that most predictors provide no explanatory contribution to the classification into the two groups. In both models, the classification performance of the factors used is very low. On the basis of the two subsamples, it can be concluded that there is no generalized tendency that the urban population is more opposed to the development of 
modern agriculture based on different attitudes and perceptions in contrast to their rural counterparts. Blanket pointing at the urban population to explain the agricultural sector's current societal problems is thus misleading, particularly since the ongoing urbanization in Germany creates a growing fraction of society that, on average, holds higher income, spends more on food, and demands high-quality food products. Therefore, agricultural communication strategies should address the entire population to explain state-of-the-art agriculture and to communicate modern food production and the various services (e.g., ecosystem services) provided by the agricultural sector.

Supplementary Materials: Used pictures of DFT in an online consumer survey are available online at: https:/ / www.caseih.com/emea/de-at/News/Pages/2016-08-30-Case-IH-stellt-auf-derFarm-Progress-Show-neues-Traktorkonzept-vor.aspx (S1), https://www.fendt.com/int/fendt-mars (S2), https: / / www.schweizerbauer.ch/landtechnik/firmen--personen/20000-melkroboter-von-lelyin-betrieb-19341.html (S3), and https:/ / melktechnik-center.com/Fuetterungstechnik/FMR-Roboter/ (S4).

Author Contributions: Conceptualization, A.G. and M.G.; formal analysis, A.G.; investigation, A.G.; data curation and validation, A.G.; writing-original draft preparation, A.G.; writing-review and editing, A.G. and M.G.; visualization, A.G.; supervision, M.G.; funding acquisition, M.G. All authors have read and agreed to the published version of the manuscript.

Funding: Research was funded by the Bavarian State Ministry for Food Agriculture and Forestry (grant number D/17/01).

Institutional Review Board Statement: The study was conducted in accordance with the General Data Protection Regulation (EU) for anonymous surveys. No personal data were processed.

Informed Consent Statement: All survey participants declared their explicit consent.

Data Availability Statement: The data presented in this study are available on request from the corresponding author.

Acknowledgments: The authors acknowledge Sebastian Schleicher for his student assistance in survey design and data collection. Thanks to Florian Klein for the assistance with data processing.

Conflicts of Interest: The authors declare no conflict of interest. The funders had no role in the design of the study; in the collection, analyses, or interpretation of data; in the writing of the manuscript; or in the decision to publish the results.

\section{References}

1. Bangel, C.; Faigle, P.; Gortana, F.; Loos, A.; Mohr, F.; Speckmeier, J.; Stahnke, J.; Venohr, S.; Blickle, P. Stadt, Land, Vorurteil. Available online: https:/ / www.zeit.de/feature/deutsche-bevoelkerung-stadt-land-unterschiede-vorurteile (accessed on 17 April 2020).

2. Deutscher Bauernverband. Situationsbericht 2018/19: Trends und Fakten zur Landwirtschaft; Deutscher Bauernverband: Berlin, Germany, 2018; pp. 1-282.

3. Grunert, K.G.; Bredahl, L.; Brunsø, K. Consumer perception of meat quality and implications for product development in the meat sector. Meat Sci. 2004, 66, 259-272. [CrossRef]

4. Sharp, J.S.; Tucker, M. Awareness and concern about largescale livestock and poultry: Results from a statewide survey of Ohioans. Rural Sociol. 2005, 70, 208-228. [CrossRef]

5. Freudenburg, W.R. Rural-Urban differences in environmental concern: A closer look. Sociol. Inq. 1991, 61, 167-198. [CrossRef]

6. Arcury, T.A.; Christianson, E.H. Rural-urban differences in environmental knowledge and actions. J. Environ. Educ. 1993, 25, 19-25. [CrossRef]

7. Pfeiffer, J.; Gabriel, A.; Gandorfer, M. Understanding the public attitudinal acceptance of digital farming technologies: A nationwide survey in Germany. Agr. Hum. Values 2021, 38, 107-128. [CrossRef]

8. Box, G.E.; Tidwell, P.W. Transformation of the independent variables. Technometrics 1962, 4, 531-550. [CrossRef]

9. Tabachnick, B.G.; Fidell, L.S. Using Multivariate Statistics, 7th ed.; Pearson Education: London, UK, 2018. 